\title{
ANALISIS SENTIMEN OPINI PUBLIK BAHASA INDONESIA TERHADAP WISATA TMII MENGGUNAKAN NAÏVE BAYES DAN PSO
}

\author{
Ratih Yulia Hayuningtyas; ${ }^{1}$ Retno Sari² \\ Teknik Informatika \\ STMIK Nusa Mandiri Jakarta \\ http://nusamandiri.ac.id/ \\ ${ }^{1}$ ratih.ryl@nusamandiri.ac.id; 2retno.rnr@nusamandiri.ac.id
}

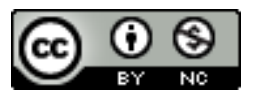

Ciptaan disebarluaskan di bawah Lisensi Creative Commons Atribusi-NonKomersial 4.0 Internasional.

\begin{abstract}
Sentiment analysis is a text analysis to identify an opinion. Public opinion or reviews are important for visitors who will travel to tourist because of the reviews will produce information about the destination. One of the tourist attractions in Indonesia that Taman Mini Indonesia Indah one of the tourist attractions that has extraordinary. Reviews about Taman Mini Indonesia Indah make it difficult for visitors to draw conclusions about information about Taman Mini Indonesia Indah. Therefore a classification method in study with Naïve Bayes and PSO methods. In study using data as many 50 positive reviews and 50 negative reviews where the results of accuracy obtained using the Naive Bayes method of 70\% while the accuracy of using Naïve Bayes and PSO is 94,02\%.
\end{abstract}

Keyword : Sentiment analysis, public opinion, Naive Bayes, PSO.

Intisari- Analisis sentimen merupakan analisis teks untuk mengidentifikasi suatu opini. Opini publik atau ulasan merupakan hal yang penting bagi pengunjung yang akan berpergian ke tempat wisata karena dari ulasan tersebut akan menghasilkan informasi mengenai objek wisata yang dituju. Salah satu tempat wisata di Indoensia yaitu Taman Mini Indonesia Indah yang merupakan salah satu tempat wisata yang memiliki daya tarik luar biasa. Ulasan mengenai Taman Mini Indoensia Indah sangat banyak sehingga menyulitkan bagi para pengunjung untuk menarik kesimpulan tentang informasi Taman Mini Indonesia Indah. Untuk itu diperlukan suatu metode klasifikasi dalam penelitian ini menggunakan metode Naïve Bayes dan PSO. Pada penelitian ini menggunakan data sebanyak 50 ulasan positif dan 50 ulasan negatif dimana hasil akurasi yang didapat menggunakan metode Naïve Bayes sebesar $70 \%$ sedangkan akurasi menggunakan Naïve Bayes dan PSO sebesar $94,02 \%$.

Kata Kunci: Analisis sentimen, opini publik, Naive Bayes, PSO.

\section{PENDAHULUAN}

Perkembangan teknologi internet membawa dampak perubahan pada beberapa sektor kehidupan manusia, mulai dari pendidikan, perdagangan, pemerintahan hingga komunikasi sosial (Hapsari, Hidayattullah, Dairoh, \& Khambali, 2018). Di era sekarang ini pertumbuhan internet dan media sosial telah berkembang pesat sehingga menyediakan berbagai informasi opini dari orang lain (Fanissa, Fauzi, \& Adinugroho, 2018).

Analisis sentimen merupakan studi yang terdiri dari natural language processing, komputasi linguistik, dan analisis teks untuk mengidentifikasi sentimen teks yang dapat membantu untuk mengidentifikasi mengenai opini (Fanissa et al., 2018). Sebuah ulasan atau opini dapat menjadi informasi sangat penting pada saat membuat keputusan atau pilihan dikarenakan informasi telah menjadi kebutuhan utama dalam kehidupan manusia (Pakpahan \& Widyastuti, 2014).

Di Indonesia terdapat banyak objek wisata yang dapat dikunjungi dimulai dari wisata alam dapat berupa, pegunungan, pantai dan laut. Selain itu ada juga objek wisata yang berupa bangunan seperti museum, candi dan lain-lain. Objek wisata merupakan suatu tempat yang memiliki daya tarik dengan tujuan menarik wisatawan berkunjung ke objek wisata tersebut. Berwisata merupakan kegiatan yang sangat digemari oleh seluruh masyarakat Indonesia (Wilianto, Pudjiantoro, \& Umbara, 2017).

Untuk memilih tempat wisata yang cocok biasanya para pengunjung akan menentukan 
terlebih dahulu tempat tujuan, serta ulasan dari tempat wisata. Ulasan dari para wisatawan yang telah berkunjung ke objek wisata merupakan hal yang terpenting karena ulasan tersebut dapat dijadikan informasi mengenai objek wisata.

Taman Mini Indonesia Indah merupakan salah satu tempat wisata yang memiliki daya tarik luar biasa, banyak sekali objek wisata yang dapat dilihat dimulai dari anjungan rumah adat, museum dan wisata alam. Setiap wisatawan yang sudah berkunjung ke Taman Mini Indonesia Indah memiliki kesan dan pesan yang berbeda-beda, kesan dan pesan ini disebut sebagai ulasan. Ulasan mengenai tempat wisata Taman Mini Indonesia Indah sangat banyak, hal ini sangat menyulitkan bagi para pengunjung yang akan berpergian ke Taman Mini Indonesia Indah untuk menarik kesimpulan.

Untuk mendapatkan kesimpulan dari sebuah opini ada beberapa yang harus dipersiapkan salah satunya yaitu dengan memilih metode klasifikasi (clasfier). Metode klasifikasi yang digunakan dalam penelitian ini yaitu Naïve Bayes, dimana metode Naïve Bayes merupakan sebuah pengklasfikasian probabilistik sederhana dengan teknik machine learning yang popular untuk klasifikasi teks (Routray, Swain, \& Mishra, 2013).

Pada penelitian sebelumnya mengenai analisis sentiment dengan menggunakan naïve bayes telah banyak dilakukan diantaranya yaitu berjudul "Analisis Sentimen Pada Review Restoran Dengan Teks Bahasa Indonesia Menggunakan Algoritma Naïve Bayes" oleh (Muthia, 2017). Penelitian ini membahas review restoran yang terdiri dari 100 review positif dan 100 review negatif yang menghasilkan nilai akurasi $86,50 \%$.

Penelitian selanjutnya dengan judul "Analisis Sentimen Dan Klasifikasi Kategori Terhadap Tokoh Publik Pada Twitter" oleh (Hidayatullah \& SN, 2014) penelitian ini membahasa review di twitter terhadap tokoh publik dengan naïve bayes yang menghasilkan akurasi $73,81 \%$ sedangkan menggunakan Suppor Vector Machine dengan nilai akurasi $83,14 \%$.

Berdasarkan uraian di atas, penelitian sebelumnya menggunakan klasifikasi Naïve Bayes dengan tingkat akurasi $86,50 \%$ dan $73,81 \%$, dalam penelitian ini analisis sentimen ulasan tempat wisata Taman Mini Indonesia Indah menggunakan metode Naïve Bayes dan Particle Swarm Optimization dengan tujuan nilai akurasi dapat meningkat.

\section{BAHAN DAN METODE}

Dalam penelitian ini menggunakan metode Naïve Bayes dan Particle Swarm Optimization, dimana dalam pengujian menggunakan Naïve
Bayes dilakukan beberapa langkah sebagai berikut:

\section{Pengumpulan Data}

Pada peneitian ini menggunakan data yang diperoleh dari web

https://www.tripadvisor.co.id/Attraction_Revi ew-g294229-d379330-Reviews-

Beautiful Indonesia in Miniature Park-

Jakarta Java.html. Pada web ini terdapat banyak ulasan mengenai Taman Mini Indonesia Indah, data yang digunakan sebanyak 50 ulasan positif dan 50 ulasan negatif. Ulasan positif dan negatif akan dijadikan data training sebagai pengujian dari data testing.

\section{Pengolahan data awal}

Pada tahap pengolahan data awal/preprocessing melalui tiga proses yaitu tokenization, stopword removal, stemming.

\section{Metode yang diusulkan}

Metode yang digunakan dalam penelitian ini yaitu metode Naïve Bayes dan PSO. Metode Naïve Bayes ini salah satu metode terbaik dalam pengklasifikasian. Naïve Bayes menggunakan statistik sederhana berdasarkan teorema bayes yang mengasumsikan keberadaan atau ketiadaan dari suatu fitur tertentu dari suatu kelas yang tidak berhubungan dengan fitur lainnya (Wilianto et al., 2017). Metode Naïve Bayes didasarkan pada probabilitas bersyarat dan kemungkinan maksimum kejadian (Karthika \& Sairam, 2015). Pada tahap ini menentukan nilai sentimen terhadap suatu ulasan kedalam dua nilai yaitu positif dan negatif.

Particle Swarm Optimization merupakan algoritma dalam mengontrol pemilihan subset yang mengarah ke akurasi yang terbaik. PSO digunakan untuk menemukan bagian fitur maksimum dengan campuran fitur terbaik dari dataset yang ada (Basari, Hussin, Ananta, \& Zeniarja, 2013).

\section{Eksperimen dan Pengujian Metode}

Eksperimen dan pengujian dengan metode Naïve Bayes menggunakan RapidMinner dimana data yang digunakan untuk eksperimen dan pengujian merupakan data training dari https://www.tripadvisor.co.id/Attraction Reviewg294229-d379330-Reviews-

Beautiful Indonesia in Miniature Park-

\akarta Java.html yang sudah dikelompokkan kedalam klasifikasi negatif dan positif. Hasil dari eksperimen dan pengujian akan ditingkatkan akurasinya dengan Particle Swarm Optimization untuk mendapatkan hasil yang terbaik. 


\section{Evaluasi dan validasi Hasil}

Pada tahapan evaluasi dan validasi hasil dari penelitian ini menggunakan 10 fold cross validation, dimana akurasi diukur dengan confusion matrix berupa kurva ROC yang digunakan untuk mengukur nilai AUC. Klasifikasi nilai AUC sebagai berikut (Gorunescu, 2011):

0,90-100 = Excellent Classification;

0,80-0,90= Good Classification;

0,70-0,80= Fair Classification;

$0,60-0,70=$ Poor Classification;

0,50-0,60= Failure;

\section{HASIL DAN PEMBAHASAN}

Pembahasan pada penelitian ini dimulai dari pengolahan data awal, metode yang digunakan, eksperimen dan pengujian metode serta evaluasi dan validasi hasil. Berikut adalah tahapannya:

\section{Pengolahan Data Awal}

\section{a. Tokenization}

Pada tahapan tokenization semua ulasan positif dan negatif dihilangkan tanda baca dan angka yang ada di data ulasan. Berikut adalah contoh dari tokenization.

Tabel 1. Hasil Tokenization

\begin{tabular}{llll}
\hline & \multicolumn{3}{c}{ Tokenization } \\
\hline pengalaman aku ke sini & pengalaman aku ke sini \\
burukk. haha karena pas & burukk haha karena pas \\
sampai hujan deras..belum & sampai hujan deras belum \\
sempat jalan2 uda & sempat jalan uda hujan mana \\
hujan..mana pas dtg itu & pas dtg itu ramee banget jalan \\
ramee banget..jalan kaki & kaki antara ke tempat lain nya \\
antara 1 ke tempat lain nya & mana jauh lagi \\
mana jauh lagi &
\end{tabular}

Sumber: (Hayuningtyas \& Sari, 2019)

\section{b. Stopword Removal}

Stopword dpat dikatakan untuk menghilangkan karakter, tanda baca, serta katakata umum yang tidak memiliki makna atau informasi yang dibutuhkan (Ling, Kencana, \& Oka, 2014). Stopword Removal dengan menghilangkan beberapa kata kerja, kata sifat, kata keterangan, dan kata penghubung seperti yang, atau, di, dengan, dan sebagainya. Berikut adalah hasil dari stopword removal.

\section{Tabel 2. Hasil Stopword Removal}

\begin{tabular}{lll}
\hline & \multicolumn{2}{c}{ Stopword Removal } \\
\hline pengalaman aku ke sini & pengalaman burukk haha pas \\
burukk.. haha karena pas & hujan deras jalan uda hujan \\
sampai hujan deras..belum & pas dtg ramee banget jalan \\
sempat jalan2 uda & kaki nya \\
hujan...mana pas dtg itu ramee & \\
banget..jalan kaki antara $1 \mathrm{ke}$ & \\
tempat lain nya mana jauh \\
lagi
\end{tabular}

Sumber: (Hayuningtyas \& Sari, 2019)

\section{c. Stemming}

Stemming merupakan salah satu proses dari mengubah token yang berimbuhan menjadi kata dasar, dengan menghilangkan semuai mbuhan yang ada pada token tersebut (Ling et al., 2014). Berikut adalah hasil dari stemming.

Tabel 3. Hasil Stemming

\begin{tabular}{llll}
\hline \multicolumn{3}{c}{ Ulasan Positif } & \multicolumn{3}{c}{ Stemming } \\
\hline Merupakan ikon wisata & $\begin{array}{l}\text { ikon wisata nasion bangsa } \\
\text { nasional bagi bangsa ini } \\
\text { sayangnya terawat danau } \\
\text { sayangnya kurang terawat. }\end{array}$ buatan kere bentang pulau \\
danau buatan yang kering & $\begin{array}{l}\text { indonesia gundukan tanah } \\
\text { sehingga bentang pulau2 di }\end{array}$ & anjungan propinsi tutup \\
indonesia terlihat hanya & informasi & kekecewaan \\
menjadi gundukan tanah. & pengunjung & \\
beberapa anjungan propinsi & & \\
yang tutup dan kurang \\
informasi \\
kekecewaan bagi pengunjung.
\end{tabular}

Sumber: (Hayuningtyas \& Sari, 2019)

\section{Metode Klasifikasi dengan Naïve Bayes}

Dalam tahapan ini menentukan klasifikasi sebuah ulasan yang termasuk ke dalam ulasan negatif atau positif. Berikut adalah contoh klasifikasi dokumen.

Tabel 4. Klasifikasi Dokumen

\begin{tabular}{llllll}
\hline Dokumen & Bagus & Budaya & Kotor & Kusam & Class \\
\hline Pos3 & 1 & 0 & 0 & 1 & Positif \\
\hline Po15 & 1 & 0 & 0 & 0 & Positif \\
\hline Pos18 & 0 & 1 & 0 & 0 & Positif \\
\hline Pos24 & 1 & 1 & 1 & 0 & Positif \\
\hline Neg2 & 1 & 0 & 1 & 1 & Negatif \\
\hline Neg12 & 0 & 0 & 1 & 0 & Negatif \\
\hline Neg21 & 0 & 1 & 0 & 1 & Negatif \\
\hline X-51 & 0 & 1 & 1 & 0 & $?$
\end{tabular}

Sumber: (Hayuningtyas \& Sari, 2019)

Menghitung probabilitas dengan dokumen neg23.

a. Probabilitas prior

$\mathrm{P}($ Class $=$ "positif" $)=4 / 7=0,57$

$\mathrm{P}($ Class $=$ "negatif" $)=3 / 7=0,43$

Untuk Class positif

$\mathrm{P}(\mathrm{x}-51 \mid$ positif $)$

$=\mathrm{P}($ bagus $=3 \mid$ positif $) * \mathrm{P}($ Budaya $=2 \mid$ positif $) * \mathrm{P}($ Ko

tor $=1 \mid$ positif $* \mathrm{P}($ Kusam $=1 \mid$ positif $)$

$=0,75 * 0,5 * 0,25 * 0,25$

$=0,0234$

Untuk Class negatif

$\mathrm{P}(\mathrm{x}-51 \mid$ negatif $)$

$=\mathrm{P}($ bagus $=1 \mid$ negatif $) * \mathrm{P}($ Budaya $=1 \mid$ negatif $) * \mathrm{P}(\mathrm{K}$

otor $=2 \mid$ negatif $) * \mathrm{P}($ Kusam $=2 \mid$ negatif $)$

$=0,33 * 0,33 * 0,67 * 0,67$ 
$=0,489$

b. Probabilitas Posterior

Untuk Class positif

$=\mathrm{P}(\mathrm{X} \mid$ positif $) * \mathrm{P}($ Class $=$ "positif" $)$

$=0,0234 * 0,57$

$=0,133$

Untuk Class negatif

$=\mathrm{P}(\mathrm{X} \mid$ negatif $) * \mathrm{P}($ Class $=$ "negatif" $)$

$=0,489 * 0,43$

$=0,21$

Kesimpulan untuk dokumen $\mathrm{x}-51$ termasuk kedalam kelas negatif.

\section{Eksperimen dan Pengujian Metode}

Eksperimen dan pengujian metode menggunakan RapidMiner. Pengujian metode menggunakan Naïve Bayes dengan eksperimen menggunakan fold cross validation 1-10 dan population 1-10. Berikut adalah hasil dari eksperimen dan pengujian metode Naïve Bayes dengan fold cross validation dan population.

Tabel 5. Akurasi dengan Naïve Bayes

\begin{tabular}{|c|c|c|c|}
\hline \multirow{2}{*}{$\begin{array}{l}\text { Cross } \\
\text { Validatio } \\
n\end{array}$} & \multirow[t]{2}{*}{ Accuracy } & \multicolumn{2}{|c|}{ Naüve Bayes } \\
\hline & & Precision & Recall \\
\hline 1 & $\begin{array}{l}67.00 \%+/- \\
7.00 \% \\
\text { (mikro: } \\
67.00 \% \text { ) }\end{array}$ & $\begin{array}{l}68.45 \%+/- \\
6.55 \% \\
\text { (mikro: } \\
68.89 \% \text { ) } \\
\text { (positive } \\
\text { class: positif) }\end{array}$ & $\begin{array}{l}\text { 62.00\%+/- } \\
10.00 \% \\
\text { (mikro: } \\
62.00 \% \text { ) } \\
\text { (positive } \\
\text { class: positif) }\end{array}$ \\
\hline 2 & $\begin{array}{l}67.00 \%+/- \\
7.00 \% \\
\text { (mikro: } \\
67.00 \% \text { ) }\end{array}$ & $\begin{array}{l}68.45 \%+/- \\
6.55 \% \\
\text { (mikro: } \\
68.89 \% \text { ) } \\
\text { (positive } \\
\text { class: positif) }\end{array}$ & $\begin{array}{l}62.00 \%+/- \\
10.00 \% \\
\text { (mikro: } \\
62.00 \% \text { ) } \\
\text { (positive } \\
\text { class: positif) }\end{array}$ \\
\hline 3 & $\begin{array}{l}63.93 \%+/- \\
5.32 \% \\
\text { (mikro: } \\
64.00 \% \text { ) }\end{array}$ & $\begin{array}{l}66.69 \%+/- \\
7.35 \% \\
\text { (mikro: } \\
66.67 \% \text { ) } \\
\text { (positive } \\
\text { class: positif) }\end{array}$ & $\begin{array}{l}55.64 \%+/- \\
13.69 \% \\
\text { (mikro: } \\
56.00 \% \text { ) } \\
\text { (positive } \\
\text { class: positif) }\end{array}$ \\
\hline 4 & $\begin{array}{l}70.00 \%+/- \\
2.00 \% \\
\text { (mikro: } \\
70.00 \% \text { ) }\end{array}$ & $\begin{array}{l}78.30 \%+/- \\
6.30 \% \\
\text { (mikro: } \\
76.32 \% \text { ) } \\
\text { (positive } \\
\text { class: positif) }\end{array}$ & $\begin{array}{l}57.53 \%+/- \\
13.23 \% \\
\text { (mikro: } \\
58.00 \% \text { ) } \\
\text { (positive } \\
\text { class: positif) }\end{array}$ \\
\hline 5 & $\begin{array}{l}66.00 \%+/- \\
4.90 \% \\
\text { (mikro: } \\
66.00 \% \text { ) }\end{array}$ & $\begin{array}{l}71.51 \%+/- \\
4.44 \% \\
\text { (mikro: } \\
71.05 \% \text { ) } \\
\text { (positive } \\
\text { class: positif) }\end{array}$ & $\begin{array}{l}54.00 \%+/- \\
13.56 \% \\
\text { (mikro: } \\
54.00 \% \text { ) } \\
\text { (positive } \\
\text { class: positif) }\end{array}$ \\
\hline 6 & $\begin{array}{l}61.15 \%+/- \\
8.32 \% \\
\text { (mikro: } \\
61.00 \% \text { ) }\end{array}$ & $\begin{array}{l}68.12 \%+/- \\
18.48 \% \\
\text { (mikro: } \\
64.10 \% \text { ) } \\
\text { (positive } \\
\text { class: positif) }\end{array}$ & $\begin{array}{l}49.74 \%+/- \\
12.58 \% \\
\text { (mikro: } \\
50.00 \% \text { ) } \\
\text { (positive } \\
\text { class: positif) }\end{array}$ \\
\hline
\end{tabular}

\begin{tabular}{|c|c|c|c|}
\hline Cross & Accuracy & \multicolumn{2}{|c|}{ Naïve Bayes } \\
\hline 7 & $\begin{array}{l}\text { 69.05\%+/- } \\
5.95 \% \\
\text { (mikro: } \\
69.00 \% \text { ) }\end{array}$ & $\begin{array}{l}79.17 \%+/- \\
14.60 \% \\
\text { (mikro: } \\
75.68 \% \text { ) } \\
\text { (positive } \\
\text { class: positif) }\end{array}$ & $\begin{array}{l}56.46 \%+/- \\
11.40 \% \\
\text { (mikro: } \\
56.00 \% \text { ) } \\
\text { (positive } \\
\text { class: positif) }\end{array}$ \\
\hline 8 & $\begin{array}{l}66.99 \%+/- \\
6.15 \% \\
\text { (mikro: } \\
67.00 \% \text { ) }\end{array}$ & $\begin{array}{l}74.14 \%+/- \\
13.65 \% \\
\text { (mikro: } \\
74.29 \% \text { ) } \\
\text { (positive } \\
\text { class: positif) }\end{array}$ & $\begin{array}{l}51.01 \%+/- \\
19.69 \% \\
\text { (mikro: } \\
52.00 \% \text { ) } \\
\text { (positive } \\
\text { class: positif) }\end{array}$ \\
\hline 9 & $\begin{array}{l}64.81 \%+/- \\
14.70 \% \\
\text { (mikro: } \\
65.00 \% \text { ) }\end{array}$ & $\begin{array}{l}72.83 \%+/- \\
23.00 \% \\
\text { (mikro: } \\
71.43 \% \text { ) } \\
\text { (positive } \\
\text { class: positif) }\end{array}$ & $\begin{array}{l}49.63 \%+/- \\
18.69 \% \\
\text { (mikro: } \\
50.00 \% \text { ) } \\
\text { (positive } \\
\text { class: positif) }\end{array}$ \\
\hline 10 & $\begin{array}{l}68.00 \%+/- \\
13.27 \% \\
\text { (mikro: } \\
68.00 \% \text { ) }\end{array}$ & $\begin{array}{l}77.83 \%+/- \\
22.49 \% \\
\text { (mikro: } \\
75.00 \% \text { ) } \\
\text { (positive } \\
\text { class: positif) }\end{array}$ & $\begin{array}{l}54.00 \%+/- \\
18.00 \% \\
\text { (mikro: } \\
54.00 \% \text { ) } \\
\text { (positive } \\
\text { class: positif) }\end{array}$ \\
\hline
\end{tabular}

Sumber: (Hayuningtyas \& Sari, 2019)

Berdasarkan tabel 5 bahwa cross validation 4 yang memiliki nilai akurasi terbesar yaitu $70.00 \%$, tetapi dengan nilai akurasi tersebut masih termasuk kedalam fair classification. Dalam penelitian ini ditambahkan Particle Swarm Optimization untuk meningkatkan akurasi dengan cross validation 2. Berikut adalah hasil akurasi dengan metode Naïve Bayes dan Particle Swarm Optimization.

Tabel 6. Akurasi dengan Naïve Bayes dan Particle Swarm Optimization

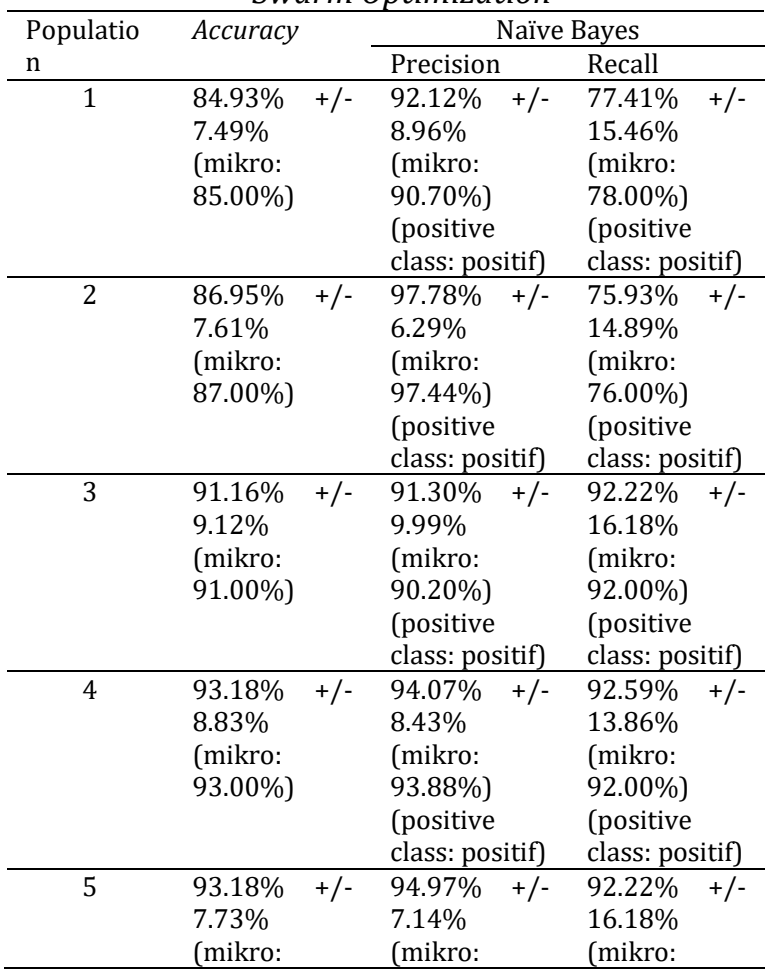




\begin{tabular}{|c|c|c|c|}
\hline Populatio & Accuracy & \multicolumn{2}{|c|}{ Naïve Bayes } \\
\hline & $93.00 \%)$ & $\begin{array}{l}93.88 \%) \\
\text { (positive } \\
\text { class: positif) }\end{array}$ & $\begin{array}{l}92.00 \%) \\
\text { (positive } \\
\text { class: positif) }\end{array}$ \\
\hline 6 & $\begin{array}{l}94.02 \% \quad+/- \\
6.02 \% \\
\text { (mikro: } \\
94.00 \%)\end{array}$ & $\begin{array}{l}92.75 \% \quad+/- \\
8.25 \% \\
\text { (mikro: } \\
92.31 \% \text { ) } \\
\text { (positive } \\
\text { class: positif) }\end{array}$ & $\begin{array}{l}95.93 \% \quad+/- \\
7.66 \% \\
\text { (mikro: } \\
96.00 \%) \\
\text { (positive } \\
\text { class: positif) }\end{array}$ \\
\hline 7 & $\begin{array}{l}93.01 \% \quad+/- \\
8.31 \% \\
\text { (mikro: } \\
93.00 \%)\end{array}$ & $\begin{array}{l}92.49 \% \quad+/- \\
8.51 \% \\
\text { (mikro: } \\
92.16 \%) \\
\text { (positive } \\
\text { class: positif) }\end{array}$ & $\begin{array}{l}94.44 \% \quad+/- \\
11.11 \% \\
\text { (mikro: } \\
94.00 \%) \\
\text { (positive } \\
\text { class: positif) }\end{array}$ \\
\hline 8 & $\begin{array}{l}94.02 \% \quad+/- \\
6.02 \% \\
\text { (mikro: } \\
94.00 \%)\end{array}$ & $\begin{array}{l}93.39 \% \quad+/- \\
10.03 \% \\
\text { (mikro: } \\
92.31 \%) \\
\text { (positive } \\
\text { class: positif) }\end{array}$ & $\begin{array}{l}95.56 \% \quad+/- \\
8.31 \% \\
\text { (mikro: } \\
96.00 \%) \\
\text { (positive } \\
\text { class: positif) }\end{array}$ \\
\hline 9 & $\begin{array}{l}94.02 \% \quad+/- \\
6.02 \% \\
\text { (mikro: } \\
94.00 \%)\end{array}$ & $\begin{array}{l}93.12 \% \quad+/- \\
7.73 \% \\
\text { (mikro: } \\
92.31 \% \text { ) } \\
\text { (positive } \\
\text { class: positif) }\end{array}$ & $\begin{array}{l}96.30 \% \quad+/- \\
10.48 \% \\
\text { (mikro: } \\
96.00 \% \text { ) } \\
\text { (positive } \\
\text { class: positif) }\end{array}$ \\
\hline 10 & $\begin{array}{l}93.10 \% \quad+/- \\
10.13 \% \\
\text { (mikro: } \\
93.00 \% \text { ) }\end{array}$ & $\begin{array}{l}93.06 \% \quad+/- \\
13.32 \% \\
\text { (mikro: } \\
90.57 \% \text { ) } \\
\text { (positive } \\
\text { class: positif) }\end{array}$ & $\begin{array}{l}95.56 \% \quad+/- \\
12.57 \% \\
\text { (mikro: } \\
96.00 \% \text { ) } \\
\text { (positive } \\
\text { class: positif) }\end{array}$ \\
\hline
\end{tabular}

Sumber: (Hayuningtyas \& Sari, 2019)

Dilihat dari tabel 6 hasil akurasi terbesar pada population 9 dengan menggunakan cross validation 9 dan maximum numbernya 30 mencapai akurasi 94.02\%.

\section{Evaluasi dan Validasi Hasil}

Dengan menggunakan Naive Bayes saja dengan menggunakan 4 Fold Cross Validation didapati akurasi sebesar 70.00\%. Confusion matrix Naive Bayes dapat dilihat pada tabel 7.

Tabel 7 Confusion Matrix Naive Bayes

\begin{tabular}{l|l|l}
\hline \multicolumn{2}{c}{ Accuracy : $70.00 \%+/-2.00 \%$ (mikro:70.00\%) } \\
\hline & True negatif & True positif \\
\hline Pred negatif & 41 & 21 \\
\hline Pred positif & 9 & 29 \\
\hline
\end{tabular}

Sumber: (Hayuningtyas \& Sari, 2019)

Sedangkan eksperimen dengan menggunakan Naive Bayes dan PSO dengan menggunakan 9 Fold Cross Validation dengan menggunaka population 9 dan maximum numbernya 30 didapati akurasi sebesar 94.02\%. Confusion matrix Naive Bayes dan PSO dapat dilihat pada tabel 8 .
Tabel 8 Confusion Matrix Naive Bayes dan PSO

\begin{tabular}{l|l|l}
\hline \multicolumn{3}{c}{ Accuracy : 94.02\%+/- 6.02\% (mikro: $94.00 \%)$} \\
\hline & True negatif & True positif \\
\hline Pred negatif & 46 & 2 \\
\hline Pred positif & 4 & 48 \\
\hline \multicolumn{3}{|l}{ Sumber: (Hayuningtyas \& Sari, 2019) }
\end{tabular}

Data uji diatas akan dinilai hasil prediksi dengan menggunakan grafik ROC. Dapat dilihat pada gambar 1 grafik ROC untuk Naive Bayes dan gambar 2 grafik ROC untuk Naive Bayes dan PSO

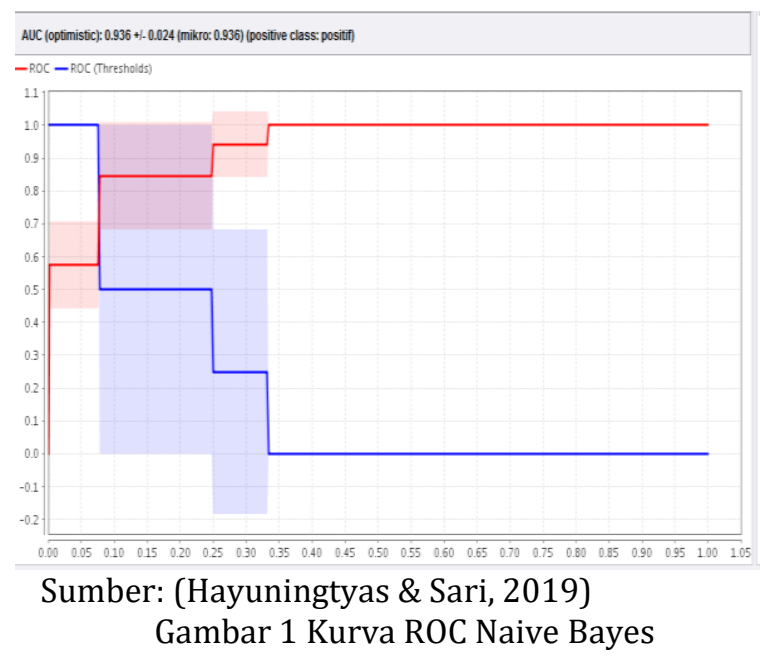

Naive Bayes berbasis PSO

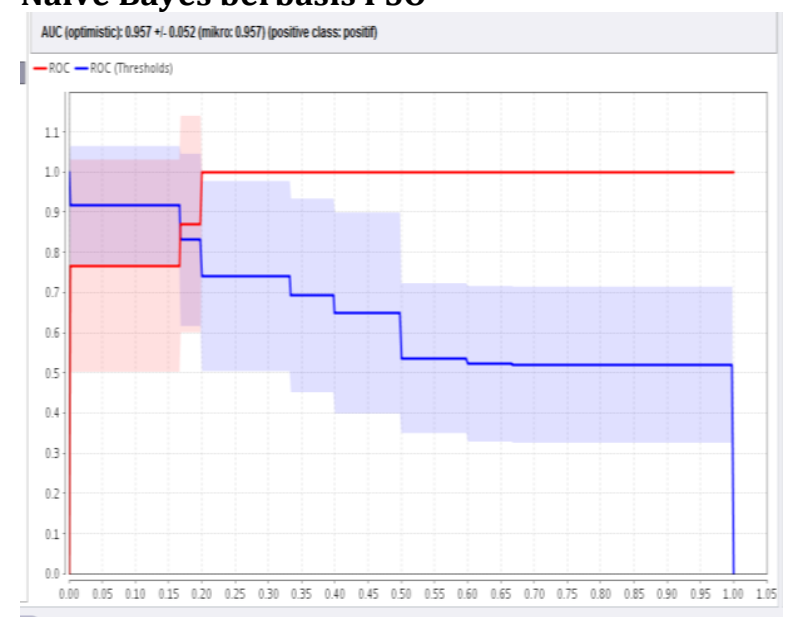

Sumber: (Hayuningtyas \& Sari, 2019)

Gambar 2 Kurva ROC Naive Bayes dan PSO

\section{KESIMPULAN}

Pada penelitian ini yang berjudul Analisis Sentimen Opini Publik Bahasa Indonesia Terhadap Wisata TMII Menggunakan Naïve Bayes Dan PSO, membandingkan akurasi yang didapat dari penggunaan 2 metode yaitu Naive Bayes dan Naive Bayes dengan PSO. Setelah dilakukan eksperimen untuk analisis sentimen opini publik 
Bahasa Indonesi Terhadap Wisata TMII dengan menggunakan Naive Bayes didapati akurasi sebesar $70 \%$ dengan menggunakan 4 fold Cross Validation. Sedangkan hasil eksperimen untuk analisis sentimen opini publik Bahasa Indonesi Terhadap Wisata TMII dengan menggunakan Naive Bayes dengan PSO didapati akurasinya sebesar 94.02\% dengan menggunaka 9 Fold Cross Validation.

\section{REFERENSI}

Basari, A. S. hasan, Hussin, B., Ananta, I. gede P., \& Zeniarja, J. (2013). Opinion Mining of Movie Review Using Hybrid Method of Support Vector Machine and Particle Swarm Optimization. In Procedia Engineering (pp. 453-462). Elsevier B.V. http://doi.org/10.1016/j.proeng.2013.02.05 9

Fanissa, S., Fauzi, M. A., \& Adinugroho, S. (2018). Analisis Sentimen Pariwisata di Kota Malang Menggunakan Metode Naive Bayes dan Seleksi Fitur Query Expansion Ranking. Jurnal Pengembangan Teknologi Informasi Dan Ilmu Komputer, 2(8), 2766-2770.

Gorunescu, F. (2011). Data Mining: Concepts, Models, and Techniques. Verlag Berlin Heidelberg: Springer.

Hapsari, Y., Hidayattullah, M. F., Dairoh, \& Khambali, M. (2018). Opinion Mining Terhadap Toko Online Di Media Sosial Menggunakan Algoritma Naïve Bayes (Studi Kasus: Akun Facebook Dugal Delivry). Jurnal Pengembangan IT (JPIT), 03(02), 233-236.

Hayuningtyas, R. Y., \& Sari, R. (2019). Analisis Sentimen Opini Publik Bahasa Indonesia Terhadap Wisata TMII Menggunakan Naive Bayes dan PSO. Laporan Akhir Penelitian Mandiri STMIK Nusa Mandiri Jakarta.

Hidayatullah, A. F., \& SN, A. (2014). Analisis Sentimen Dan Klasifikasi Kategori Terhadap Tokoh Publik Pada Twitter. In Seminar Nasional Informatika (pp. 115-122). Retrieved from http://www.situs.com

Karthika, S., \& Sairam, N. (2015). A Naïve Bayesian Classifier for Educational Qualification. Indian Journal of Science and Technology, 8(16), $1-5$. http://doi.org/10.17485/ijst/2015/v8i16/6 2055
Ling, J., Kencana, I. P. E. N., \& Oka, T. B. (2014). Analisis Sentimen Menggunakan Metode Naive Bayes Classifier Dengan Seleksi Fitur Chi Square. E-Jurnal Matematika, 3(3), 9299.

Muthia, D. A. (2017). Analisis Sentimen Pada Review Restoran Dengan Teks Bahasa Indonesia Mengunakan Algoritma Naive Bayes. Jurnalilmu Pengetahuan Dan Teknologi Komputer, 2(2), 39-45. http://doi.org/10.1515/HUMOR.2006.009

Pakpahan, D., \& Widyastuti, H. (2014). Aplikasi Opinion Mining dengan Algoritma Naïve Bayes untuk Menilai Berita Online. Jurnal Integrasi, 6(1), 1-10.

Routray, P., Swain, C. K., \& Mishra, S. P. (2013). A Survey on Sentiment Analysis. International Journal of Computer Applications, 76(10), 18.

Wilianto, L., Pudjiantoro, T. H., \& Umbara, F. R. (2017). Analisis Sentimen Terhadap Tempat Wisata Dari Komentar Pengunjung Dengan Menggunakan Metode Naïve Bayes Classifier Studi Kasus Jawa Barat. Prosiding SNATIF, 439-448. 